\title{
Nematicidal activity of menthol and its dithiophosphoric derivatives
}

\author{
Evgeny Nikitin ${ }^{1, *}$, Georgiy Shumatbaev ${ }^{1}$, Alsu Gatiyatullina ${ }^{2}$, Anastasia Egorova $^{2}$, and \\ Ramazan Salikhov ${ }^{3}$ \\ ${ }^{1}$ Federal State Budgetary Institution of Science, Federal Research Center, Kazan Scientific Center of \\ Russian Academy of Sciences, 420111 Kazan, Russian Federation \\ ${ }^{2}$ Research Institute for Problems of Ecology and Mineral Wealth Use of Tatarstan Academy of \\ Sciences, 420087 Kazan, Russian Federation \\ ${ }^{3}$ A.M. Butlerov Chemical Institute, Kazan Federal University, 420008 Kazan, Russian Federation
}

\begin{abstract}
The effects of $(-)-(1 R, 2 S, 5 R)$-menthol and its dithiophosphoric derivatives - O,O-di-(-)-menthyldithiophosphoric acid, its sodium, $8 S, 9 R$ quinine, $(S)-(-)$-nicotinic and pyridoxonium salts on the organism of the free-living soil nematode Caenorhabditis elegans were investigated. (-)$(1 R, 2 S, 5 R)$-menthol had no toxic effect on nematodes. O,O-di-(-)menthyldithiophosphoric acid and its sodium salt caused dose-dependent death of nematodes. The toxic effect of these substances on the C. elegans organism developed with a lag-phase and reached its maximum value after 24 hours at concentrations of O,O-di-(-)-menthyldithiophosphoric acid and its sodium salt of 500 and $400 \mu \mathrm{g} / \mathrm{mL}$, respectively. The $\mathrm{LC}_{50}$ values were $191.5 \mu \mathrm{g} / \mathrm{mL}$ for O,O-di-(-)-menthyldithiophosphoric acid, and 181.6 $\mu \mathrm{g} / \mathrm{mL}$ for its sodium salt. $8 S, 9 R$-quinine, (S)-(-)-nicotinium and pyridoxonium salts of O,O-di-(-)-menthyldithiophosphoric acid were less toxic against $C$. elegans, causing $89.5-98.5 \%$ death of nematodes upon 24 hour exposure at a concentration of $2000 \mu \mathrm{g} / \mathrm{mL}$. The study of the antihelmintic properties of $(-)-(1 R, 2 S, 5 R)$-menthyl dithiophosphoric derivatives is promising for the creation of drugs both for the treatment of helminthiasis in domestic animals and humans, and as well as nematicides to control phytonematodes parasitizing in plants.
\end{abstract}

\section{Introduction}

Nematodes are some of the most common invertebrates on Earth, found in a wide variety of environments. At the present time, there are more than 24,000 species of freeliving and parasitic nematodes [1]. According to the World Health Organization, at least 2 billion people are affected by various helminthiases, 135 thousand people die annually from helminthiases. The annual damage caused by helminths to livestock and crop production is estimated at several billion dollars. Nematodes are capable of infecting various organs of humans and animals. In case of pasture breeding of animals, intestinal helminthiases pose a

\footnotetext{
* Corresponding author: berkutru@mail.ru
} 
serious danger [2]. Angiostrongylus vasorum, Crenosoma vulpis, Capillaria aerophila, and Aelurostrongylus abstrusus nematodes affect the cardiovascular and respiratory systems of domestic animals [3]. The negative effect of nematodes on the growth and development of young farm animals has been established [5, 6]. In cows infected with gastrointestinal nematodes, productivity decreases due to a decrease of protein content in milk [4]. The overall prevalence of parasites in horses is $77.9 \%$ [7]. In pigs of all age groups, infections caused by ascaris can occur, which reduces productivity $[8,9]$. Plant parasitic nematodes change the microbial communities of the rhizosphere and disrupt plant metabolism, which leads to a decrease in yield up to $70 \%[10]$.

At the present time, the main method for the treatment of humans and farm animals helminthiases is the use of synthetic antihelmintic drugs, such as benzimidazoles (mebendazole, albendazole, fenbendazole and flubendazole), imidazothiazoles (levamisole, pyrantel), macrocyclic lactones (ivermectin, moxidectin), amino-acetonitrile derivatives (monepantel) [11, 12], as well as their combinations [13]. As a result of the uncontrolled use of synthetic antihelmintic drugs, the forms of helminths have appeared that are resistant to albendazole and levamisole, thiabendazole, ivermectin [14-16]. A decrease in the effectiveness of thiabendazole, levamisole and ivermectin in the treatment of helminthiasis in sheep in England and Scotland has been shown [15, 16]. Fenbendazole, closantel and ivermectin have shown low efficiency in the treatment of helminthiasis in sheeps and goats in the Kashmir Valley [17]. At the present time, overcoming the drug resistance of helminths is an actual problem. One of the ways to solve this problem can be use of secondary plant metabolites and their derivatives [18]. In folk medicine, along with tansy, wormwood and elecampane, mint is used to treat helminthiasis [19].

The search for new antihelmintic drugs is hampered by the possibility of testing them in laboratory conditions. The use of parasitic nematodes as test organisms is associated with the difficulty and danger of their cultivation in the laboratory. At the present time, for studying the nematicidal activity of drugs, the free-living soil nematode Caenorhabditis elegans is used, which is similar to parasitic nematodes in the general plan of body structure and neurochemistry [20].

Our research group curries out systematic research on the creation of biologically active drugs based on dithiophosphoric acids and their salts using nitrogenous organic compounds [21-24], many of these acids were obtained from monoterpene alcohols. We assumed that dithiophosphoric acids obtained from enantiomerically pure menthols and their salts can be of interest for studying nematicidal activity.

The aim of this work was to evaluate the nematicidal activity of $(-)-(1 R, 2 S, 5 R)$-menthol and its dithiophosphoric derivatives in experiments with C. elegans.

\section{Materials and methods}

We have studied the nematicidal activity of $(-)-(1 R, 2 S, 5 R)$-menthol, the main component of the mint essential oil (Mentha arvensis L.). (-)-(1R,2S,5R)-menthol 1, 8S,9R-quinine 6, $(S)-(-)$-nicotine 7 , pyridoxine $\mathbf{8}$, and tetraphosphorus decasulfide $\mathbf{2}$ were purchased from Sigma-Aldrich.

O,O-di-(-)-menthyldithiophosphoric acid 3 was obtained by the method [25]. The syntheses of $(S)-(-)$-nicotinic, pyridoxinic and $8 S, 9 R$-quinine salts of O,O-di-(-)dimenthyldithiophosphoric acid 9-11 were carried out according to the methods presented in articles [21] and [26].

The sodium salt of O,O-di-(-)-menthyldithiophosphoric acid 5 was obtained by the neutralization reaction of acid 3 with sodium hydroxide 4 in the 1:1 ratio. For this purpose, 
a solution of sodium hydroxide $\mathbf{4}$ in ethanol was added by dropwise to a solution of O,O-di(-)-dimenthyldithiophosphoric acid $\mathbf{3}$ in ethanol with vigorous stirring and cooling for 1 hour. The completeness of the reaction was monitored by the ${ }^{31} \mathrm{P}\left\{{ }^{1} \mathrm{H}\right\}$ NMR spectroscopy until the signal of $\mathrm{O}, \mathrm{O}-\mathrm{di}-(-)$-dimenthyldithiophosphoric acid 3 was disappeared at $\delta_{\mathrm{P}} 85.8$ ppm. The structures of the compounds obtained are shown in Fig. 1.

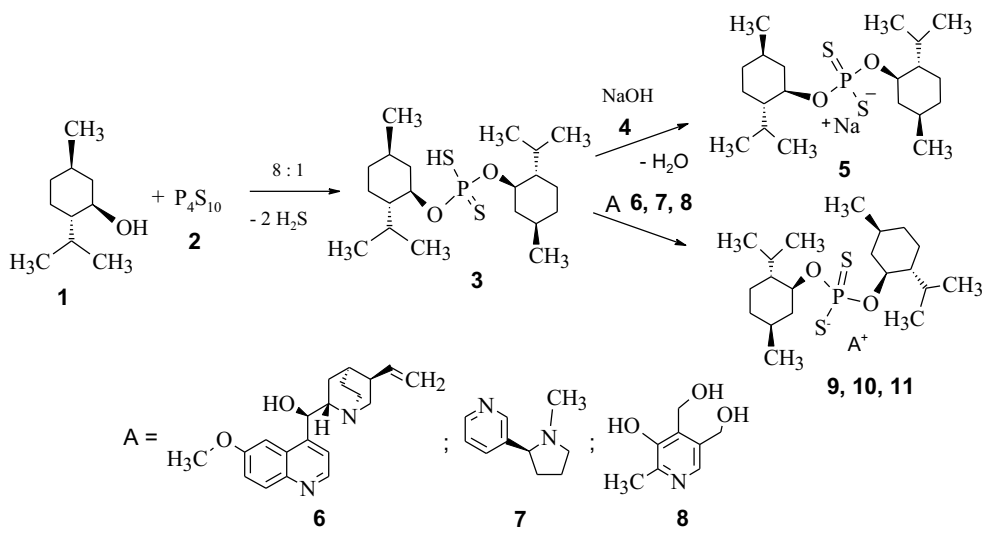

Fig. 1. The scheme of the synthesis of dithiophosphoric derivatives of $(-)-(1 R, 2 S, 5 R)$-menthol.

Experiments to determine the toxicity of $(-)-(1 R, 2 S, 5 R)$-menthol $\mathbf{1}$ and its derivatives $\mathbf{3}$, 5, 9, 10, and 11 were carried out on the free-living soil nematode Caenorhabditis elegans, the wild-type N2 Bristol strain. Nematodes were grown at $22^{\circ} \mathrm{C}$ on a standard medium (3 $\mathrm{g} / \mathrm{L} \mathrm{NaCl}, 17 \mathrm{~g} / \mathrm{L}$ Bactoagar, $2.5 \mathrm{~g} / \mathrm{L}$ Bactopeptone, $5 \mathrm{mg} / \mathrm{L}$ cholesterol, $1 \mathrm{mM} \mathrm{CaCl}, 1 \mathrm{mM}$ $\mathrm{MgSO}_{4}, 25 \mathrm{mM}$ potassium phosphate buffer with $\mathrm{pH}$ 6.0) [27]. E. coli OP50 was used for feeding the nematodes [27]. The experiments were carried out with young adult nematodes at $22^{\circ} \mathrm{C}$ in $\mathrm{M} 9$ buffer $\left(3 \mathrm{~g} / \mathrm{L} \mathrm{KH}_{2} \mathrm{PO}_{4}, 6 \mathrm{~g} / \mathrm{L} \mathrm{Na}_{2} \mathrm{HPO}_{4}, 5 \mathrm{~g} / \mathrm{L} \mathrm{NaCl}, 1 \mathrm{mM} \mathrm{MgSO}\right.$ ) [27]. In the each experiment, nematodes were washed off from agar surface with M9 buffer into a $40 \mathrm{~mm}$ Petri dish and washed off from the growth medium, bacteria, and metabolites. For this purpose, the number of nematodes required for the experiment were transferred using an automatic pipette into a $10 \mathrm{~mL}$ glass centrifuge tube, where $10 \mathrm{~mL}$ of $\mathrm{M} 9$ buffer was added. After the nematodes had settled to the bottom of the tube, the supernatant was removed and $10 \mathrm{~mL}$ of $\mathrm{M} 9$ buffer was added again. This procedure was repeated three times. The total washing time was about $30 \mathrm{~min}$. After washing, the nematodes were transferred into a clean Petri dish $40 \mathrm{~mm}$ in diameter with M9 buffer and seated with an automatic pipette, 50 faces in each, into $10 \mathrm{~mL}$ glass centrifuge tubes. After settling of the nematodes to the bottom of the tube (within 5-10 min), the entire supernatant was removed, $1 \mathrm{~mL}$ of M9 buffer and the test substances were added. The corresponding amount of solvent was added to the control variant. The nematodes were incubated with toxicants at $22^{\circ} \mathrm{C}$. The quantity of dead nematodes was counted at fixed time intervals. Nematodes that did not exhibit spontaneous locomotor activity and did not respond to touching with a thin needle were considered dead. The experiments were performed in duplicate. To compare the toxicity of the test substances, the $\mathrm{LC}_{50}$ was calculated using the Körber method [28].

\section{Results and discussion}

The results of the toxicity experiments of $(-)-(1 R, 2 S, 5 R)$-menthol and its dithiophosphoric derivatives on $C$. elegans are shown in Tables 1 and 2 . It was found that $(-)-(1 R, 2 S, 5 R)-$ mentol at concentrations of 125,250 and $500 \mu \mathrm{g} / \mathrm{mL}$ does not have a toxic effect on nematodes after 24 hours of incubation (Table 1). The toxic effect of O,O-di-(-)- 
menthyldithiophosphoric acid and its sodium salt has developed over time. After two hours of incubation with toxicants, the quantity of dead nematodes did not differ from the control variant. After six-hour exposure of O,O-di-(-)-menthyldithiophosphoric acid at a concentration of $500 \mu \mathrm{g} / \mathrm{mL}$ and sodium salt of O,O-di-(-)-menthyldithiophosphoric acid at a concentration of $400 \mu \mathrm{g} / \mathrm{mL}$ caused the death of 91 and $88 \%$ of nematodes, respectively (Table 1). After 24 hours, O,O-di-(-)-menthyldithiophosphoric acid at a concentration of $125 \mu \mathrm{g} / \mathrm{mL}$ and sodium salt of O,O-di-(-)-menthyldithiophosphoric acid at a concentration of $100 \mu \mathrm{g} / \mathrm{mL}$ led to the death of one third of the nematodes (Table 1). At concentrations of $250 \mu \mathrm{g} / \mathrm{mL}$ and $200 \mu \mathrm{g} / \mathrm{mL}$, respectively, these compounds caused the death of $90 \%$ of nematodes (Table 1). An increase in the concentration of O,O-di-(-)menthyldithiophosphoric acid up to $500 \mu \mathrm{g} / \mathrm{mL}$ and sodium salt of O,O-di-(-)menthyldithiophosphoric acid to $400 \mu \mathrm{g} / \mathrm{mL}$ led to $100 \%$ death after 24 hours exposure (Table 1).

Table 1. Toxic effect of (-)-(1R,2S,5R)-menthol, O,O-di-(-)-menthyldithiophosphoric acid and sodium salt of $\mathrm{O}, \mathrm{O}-\mathrm{di}-(-)$-menthyldithiophosphoric acid on C. elegans

\begin{tabular}{|l|c|c|c|}
\hline \multirow{2}{*}{ Experiment conditions } & \multicolumn{3}{|c|}{ Rate of dead nematodes, \% } \\
\cline { 2 - 4 } Compounds/concentration, $\mu \mathrm{g} / \mathrm{mL}$ & 2 hours & 6 hours & 24 hours \\
\hline Control & $1.5 \pm 0.8$ & $3.5 \pm 1.3$ & $8.5 \pm 1.9$ \\
$\mathbf{1} 125$ & $2.0 \pm 0.9$ & $4.5 \pm 1.5$ & $14.0 \pm 2.5$ \\
$\mathbf{3} 125$ & $1.5 \pm 0.8$ & $5.0 \pm 1.5$ & $29.0 \pm 3.2$ \\
$\mathbf{5} 100$ & $0.5 \pm 0.4$ & $4.5 \pm 1.5$ & $35.0 \pm 3.4$ \\
\hline Control & $5.5 \pm 1.1$ & $9.0 \pm 1.4$ & $13.8 \pm 1.7$ \\
$\mathbf{1} 250$ & $6.3 \pm 1.2$ & $10.0 \pm 1.5$ & $15.3 \pm 1.8$ \\
$\mathbf{3} 250$ & $3.3 \pm 0.9$ & $13.5 \pm 1.7$ & $93.0 \pm 1.3$ \\
$\mathbf{5} 200$ & $0.8 \pm 0.4$ & $12.5 \pm 1.6$ & $91.0 \pm 1.4$ \\
\hline Control & $10.0 \pm 2.1$ & $13.5 \pm 1.4$ & $15.5 \pm 2.6$ \\
$\mathbf{1} 500$ & $15 \pm 2.5$ & $20.0 \pm 2.8$ & $51.5 \pm 3.5$ \\
$\mathbf{3} 500$ & $4.0 \pm 1.4$ & $91.0 \pm 2.0$ & 100 \\
$\mathbf{5} 400$ & $1.5 \pm 0.9$ & $88.0 \pm 2.3$ & 100 \\
\hline
\end{tabular}

8S,9R-quinium, (S)-(-)-nicotinium and pyridoxonium salts of O,O-di-(-)menthyldithiophosphoric acid 6, 7 and $\mathbf{8}$ caused a dose-dependent death of nematodes after 24 hours of exposure to toxicants (Table 2). It was found that 24-hour exposure of $C$. elegans toward salts $\mathbf{6 , 7}$, and $\mathbf{8}$ at concentrations of 250 and $500 \mu \mathrm{g} / \mathrm{mL}$ did not cause a significant increase in the rate of dead nematodes as compared with the control variant (not shown). An exception is pyridoxonium salt $\mathbf{8}$, which at concentrations of 250 and 500 $\mu \mathrm{g} / \mathrm{mL}$ caused the death of 9.5 and $17.5 \%$ of nematodes, respectively, and less than $3 \%$ of the specimens died in the control variant. An increase in concentration up to $2000 \mu \mathrm{g} / \mathrm{mL}$ led to an increase in the rate of dead nematodes to $89.5-98.5 \%$ (Table 2). At the same time, toxicity decreased in the following order: $8 S, 9 R$-quinine salt $6>(S)-(-)$-nicotinium salt $7>$ pyridoxium salt 8 . In general, the toxicity of $8 S, 9 R$-quininium, $(S)-(-)$-nicotinium and pyridoxonium salts of $\mathrm{O}, \mathrm{O}-\mathrm{di}-(-)$-menthyldithiophosphoric acid turned out to be higher than that of $(-)-(1 R, 2 S, 5 R)$-menthol, but significantly lower than that of O,O-di-(-)menthyldithiophosphoric acid and its sodium salt, since the concentrations of toxicants causing death of almost $100 \%$ of nematodes during 24 hour exposure differ by $4-5$ times (Tables 1 and 2).

Table 2. Toxic effect of $8 S, 9 R$-quinium, $(S)$-(-)-nicotinium and pyridoxonium salts of O,O-di-(-)methyldithiophosphoric acid on C. elegans at 24 hour exposure

\begin{tabular}{|l|l|l|l|}
\hline \multicolumn{3}{|c|}{ Rate of dead nematodes, \% } \\
\hline \multirow{3}{*}{ Control } & $\begin{array}{l}8 S, 9 R \text {-quinium salt of O,O- } \\
\text { di-(-)-ethyldithiophosphoric } \\
\text { acid } \mathbf{6}, 2000 \mu \mathrm{g} / \mathrm{mL}\end{array}$ & $\begin{array}{l}(S)-(-) \text {-nicotinium salt of O,O- } \\
\text { di-(-)-menthyldithiophosphoric } \\
\text { acid 7,2000 } \mu \mathrm{g} / \mathrm{mL}\end{array}$ & $\begin{array}{l}\text { Pyridoxonium salt of O,O-di- } \\
(-) \text {-menthyldithiophosphoric } \\
\text { acid } \mathbf{8}, 2000 \mu \mathrm{g} / \mathrm{mL}\end{array}$ \\
\hline $23.5 \pm 3.0$ & $98.5 \pm 0.9$ & $97.5 \pm 1.1$ & $89.5 \pm 2.2$ \\
\hline
\end{tabular}


The synthetic nematicides are known to be highly toxic toward $C$. elegans: $\mathrm{LC}_{50}$ for levamisole, ivermectin, and albendazole are $1.4,1.2$, and $7.2 \mu \mathrm{g} / \mathrm{mL}$, respectively [29]. In our experiment, to calculate the $\mathrm{LC}_{50}$, we used 4 concentrations of O,O-di-(-)menthyldithiophosphoric acid and sodium salt of O,O-di-(-)-menthyldithiophosphoric acid: $50,125,250$ and $500 \mu \mathrm{g} / \mathrm{mL}$. The nematodes were incubated for 24 hours at $22^{\circ} \mathrm{C}$. The concentrations of toxicants were selected in such a way that the lowest of them did not cause the death of nematodes, and the highest led to the death of $100 \%$ of the specimens. The $\mathrm{LC}_{50}$ values determined by the Körber method were $191.5 \mu \mathrm{g} / \mathrm{mL}$ for O,O-di-(-)menthyldithiophosphoric acid, and $181.6 \mu \mathrm{g} / \mathrm{mL}$ for the sodium salt of O,O-di-(-)methyldithiophosphoric acid.

It is noteworthy that drugs based on plant raw materials for the treatment of helminthiasis in humans and animals, in contrast to synthetic drugs, do not lead to rapid addiction of parasites to them. The searches for substances with potential nematicidal activity among the secondary metabolites of plants and the obtaining of their derivatives to increase the effectiveness of antihelmintic action are promising.

One of the examples of directed changes in the biological activity of secondary plants metabolites is known to be the creation of several generations of pyrethroids. Pyrethroids are known to be derivatives of pyrethrins - substances found in Dalmatian chamomile Pyrethrum cinerariaefolium, cinerarii folium tansy Tanacetum cinerariifolium and some other plants of the Compositae family. For several decades, a large number of substances with a wider spectrum of insecticidal activity and higher toxicity than pyrethrins have been synthesized [30].

In our experiments, $(-)-(1 R, 2 S, 5 R)$-menthol contained in many plants had no toxic effects on the free-living soil nematodes $C$. elegans, while such derivatives of (-)$(1 R, 2 S, 5 R)$-menthol as $\mathrm{O}, \mathrm{O}-\mathrm{di}-(-)$-menthyldithiophosphoric acid and sodium salt of $\mathrm{O}, \mathrm{O}-$ di-(-)-methyldithiophosphoric acid caused dose-dependent death of nematodes. The toxic effect of these substances on $C$. elegans developed with a lag-phase and reached its maximum value after 24 hours at concentrations of $\mathrm{O}, \mathrm{O}-\mathrm{di}-(-)$-menthyldithiophosphoric acid and sodium salt of O,O-di-(-)-methyldithiophosphoric acid of 500 and $400 \mu \mathrm{g} / \mathrm{mL}$, respectively (Table 1). $8 S, 9 R$-quininium, $(S)-(-)$-nicotinium and pyridoxonium salts of O,O-di-(-)-menthyldithiophosphoric acid 6, 7, and 8 turned out to be less toxic for $C$. elegans, causing death $89.5-98.5 \%$ of nematodes at a concentration of $2000 \mu \mathrm{g} / \mathrm{mL}$ (Table 2). A systematic study of the antihelmintic properties of dithiophosphoric derivatives of (-)$(1 R, 2 S, 5 R)$-menthol will make it possible to establish compounds with high biological activity that can be used both as drugs for the treatment of helminthiases in animals and humans, and as nematicides to control phytonematodes parasitizing in plants.

The perspectives of this work are that O,O-di-(-)-menthyldithiophosphoric acid and sodium salt of $\mathrm{O}, \mathrm{O}-\mathrm{di}-(-)$-menthyldithiophosphoric acid are promising for further study in terms of their possible use as drugs as in treatment of helminthiases in humans and animals, and the creation of pesticides on their basis to control root and gall nematodes in plants.

\section{Conclusions}

1. The absence of toxic effect of $(-)-(1 R, 2 S, 5 R)$-menthol on the free-living soil nematode C. elegans was established.

2. O,O-Di-(-)-menthyldithiophosphoric acid and its sodium salt have a toxic effect on nematodes. The toxic effect of these compounds was revealed in the death of nematodes, which reached a maximum after 24 hours of incubation with O,O-di-(-)menthyldithiophosphoric acid and sodium salt of O,O-di-(-)-menthyldithiophosphoric acid at concentrations of 500 and $400 \mu \mathrm{g} / \mathrm{mL}$, respectively. 
3. 8S,9R-quininium, (S)-(-)-nicotinium and pyridoxonium salts of O,O-di-(-)menthyldithiophosphoric acid were less toxic to $C$. elegans, causing the death of $89.5-$ $98.5 \%$ of nematodes in concentration $2000 \mu \mathrm{g} / \mathrm{mL}$.

4. The free-living soil nematode C. elegans seems to be a convenient model organism to study the nematicidal activity of plant secondary metabolites and their derivatives.

\section{References}

1. Z.-Q. Zhang, Zootaxa, 3703(1), 1 (2013)

2. M. Rashid, M. Rashid, H. Akbar, L. Ahmad, M. Hassan, K. Ashraf, K. Saeed, M. Gharbie, Parasitology, 146(2), 129 (2019)

3. L. Lemming, A.C. Jorgensen, LB. Nielsen, S.T. Nielsen, H. Mejer, M. Chriél, H.H. International Journal for Parasitology: Parasites and Wildlife, 13, 90 (2020)

4. K. May, K. Brugemann, S. Konig, C. Strube, Veterinary Parasitology, 245(15), 119 (2017)

5. V.H. Suarez, M.R. Busetti, M.C. Fort, Veterinary Parasitology, 42(1-2), 73 (1992)

6. B.E. Stromberg, L.C. Gasbarre, A. Waite, D.T. Bechtol, M.S. Brown, N.A. Robinson, E.J. Olson, H. Newcom, Veterinary Parasitology, 183(3-4), 284 (2012)

7. A.V. Mancera, M.A. Perez, P.M. Mendoza, K.H. Guzman, J.A. Figueroa-Castillo, A.R. Palomar, Parasitology International, 81, 102265 (2021)

8. J. Boes, A. Kanora, K.T. Havn, S. Christiansen, K. Vestergaard-Nielsen, J. Jacobs, L. Alban, Veterinary Parasitology, 172, 269 (2010)

9. O.M. Hale, T.B. Stewart, Anim. Sci., 60, 220 (1985)

10. R.A. Wilschut, S. Geisen, Trends in Plant Science (2020)

11. A. Harder, Parasitol. Res., 88, 272 (2002)

12. M. Zajickova, L.T. Nguyen, L. Skalova, L.R. Stuchlikova, P. Matouskova, Drug Discovery Today, 25(2), 430 (2020)

13. T.G. Geary, B.C. Hosking, P.J. Skuce, G. Samson-Himmelstjerna, S. Maeder, P. Holdsworth, W. Pomroy, J. Vercruysse, Veterinary Parasitology, 190(1-2), 306 (2012)

14. E.S.E. Mitchell, K.R. Hunt, R. Wood, B. McLean, Vet. Rec., 166, 650 (2010)

15. D.J. Bartley, E. Jackson, K. Johnston, R.L. Coop, G.B.B. Mitchell, J. Sales, F. Jackson, Veterinary Parasitology, 117, 61 (2003)

16. D.J. Bartley, A.L. Donnan, E. Jackson, N. Sargison, G.B.B. Mitchell, F. Jackson, Veterinary Parasitology, 137, 112 (2006)

17. S.J. Bihaqi, I.M. Allaie, M.A.A. Banday, M. Sankar, Z.A. Wani, A. Prasad, Parasite Epidemiology and Control, 11 (2020)

18. F.O. Santos, A P. Morais Cerqueira, A. Branco, M.J. Moreira Batatinha, M.B. Botura, Parasitology, 146(10) 1233 (2019)

19. K.V. Tolochko, L.I. Vyshnevska, Int. J. Green Pharm., 11(3) 154 (2017)

20. J.A. Dent, Biotechnol. Bioprocess Eng., 6, 252 (2001)

21. T. Dang, I.S. Nizamov, R.Z. Salikhov, L.R. Sabirzyanova, V.V. Vorobev, T.I. Burganova, M.M. Shaidoullina, E.S. Batyeva, R.A. Cherkasov, T.I. Abdullin, Bioorganic and Medicinal Chemistry, 25(1), 100 (2019)

22. I.S. Nizamov, E.N. Nikitin, R.F. Faskhetdinov, R.A. Cherkasov, E.S. Batyeva, Russian Journal of Organic Chemistry, 51(6), 899 (2015) 
23. I.S. Nizamov, G.G. Shumatbaev, I.D. Nizamov, R.Z. Salikhov, Y.N. Nikitin, M.P. Shulaeva, R. A. Cherkasov, Chemistry Select, 4(5), 1681 (2019)

24. I.S. Nizamov, I.D. Timushev, R.Z. Salikhov, I.D. Nizamov, Y.N. Nikitin, M.P. Shulaeva, O.K. Pozdeev, T.Y. Voznesenskaya, E.S. Batyeva, R.A. Cherkasov. Asian J. Chem., 32(2) 329 (2020)

25. I.S. Nizamov, A.V. Sofronov, L.A. Al'metkina, R.A. Cherkasov, R.Z. Musin, Russian Journal of General Chemistry, 80(8), 1722 (2010)

26. I.S. Nizamov, R.Z. Salikhov, I.D. Nizamov, V.Y. Yakimov, R.A. Cherkasov, E.S. Batyeva, G.G. Sergeenko, Russian Journal of General Chemistry, 88(11), 2307 (2018)

27. S. Brenner, Genetics, 77, 71 (1974)

28. S. K. Kulkarni, Hand book of experimental pharmacology. 3rd Ed., 168 (1999)

29. J.D. Vildina, J. Kalmobe, B. Djafsia, T.J. Schmidt, E. Liebau, D. Ndjonka, Molecules, 22, 748 (2017)

30. K. Ujihara, J. Pestic. Sci., 44, 215 (2019) 